\title{
A Case Report of Radical Prostatectomy in Large Prostate Volume
}

\section{Büyük Volümlü Prostatta Radikal Prostatektomi Olgu Sunumu}

\author{
Taha Numan Yıkılmaz ${ }^{1}$, Eşref Oğuz Güven ${ }^{1}$, Erdem Öztürk $^{1}$, Halil Başar ${ }^{1}$ \\ ${ }^{1}$ Abdurrahman Yurtarslan Ankara Onkoloji Eğitim ve Araştırma Hastanesi
}

Dergiye Ulaşma Tarihi:19.01.2016 Dergiye Kabul Tarihi:17.02.2016 Doi: 10.5505/aot.2017.15870

\section{ÖZET}

Radikal prostatektomi uygulanan olgularda prostat volümünün onkolojik ve fonksiyonel sonuçlara etkisi bulunmaktadır. Büyük hacimli prostata sahip olgular da radikal prostatektominin zorlukları mevcuttur. Bu olgu sunumunda büyük prostatlı hastaya radikal prostatektomi yapılmış ve fonksiyonel ve onkolojik sonuçlara volümün etkisi araştırılmıştır.

Anahtar kelimeler: prostat kanseri, radikal prostatektomi, büyük prostat

\begin{abstract}
Prostate volume has an impact on oncologic and functional outcomes in patients who underwent radical prostatectomy. There are the challenges of radical prostatectomy in patients with large-volume prostate. In this report radical prostatectomy was underwent in patients with large prostates and volume effects were investigated in functional and oncologic results.
\end{abstract}

Keywords: prostate carcinoma, radical prostatectomy, large prostate

\section{Giriş}

Prostat kanseri Avrupalı erkeklerde görülen en sık solid organ tümörüdür (1). Sıklıkla 65 yaş üzerinde görülmekte ve uzun seyirli bir hastalıktır (2). Tedavisinde farklı yöntemler bulunmakla birlikte hangi yöntemin seçileceği konusunda ç̧eşitli faktörler değerlendirilmektedir. Prostat büyüklüğü de bunlardan biridir. Büyük prostat hacmi varlığının fonksiyonel ve onkolojik sonuçlar üzerinde negatif etkisi olabileceği bilinmektedir (3-5). Büyük prostatlarda diseksiyonun zorlaşması nedeni ile nörovasküler demetin korunması güçleşmekte ve daha fazla kanama olacağından dolayı hastanın erektil fonksiyonunun korunmasında güçlükler ortaya çıkabilmektedir (6). Bu olgu sunumunda 180 gram prostat volümüne sahip 70 yaşındaki hasta sunulmuştur.

\section{Olgu}

Alt üriner semptomlar nedeni ile kliniğimize başvuran 70 yaşındaki erkek hastanın yapılan tetkiklerinde prostat spesifik antijen(PSA) değeri $18.63 \mathrm{ng} / \mathrm{mL}$ saptand. Rektal tuşede özellik saptanmayan hastaya 12 kadran transrektal prostat biyopsisi uygulandı. Sağda 5 kadranda \%50 ile 90 arasında değişen Gleason 4+3 prostat adenokarsinom saptand1. Evreleme amaçlı hastaya kontrastlı abdominal bilgisayarlı tomografi (BT) ve tüm vücut kemik sintigrafi (TVKS) yapıldı. Hastanın BT'sinde metastaz lehine bulgu saptanmadı. Ancak prostat volümü $64 \times 82 \times 76 \mathrm{~mm}$ boyutlarında ve $200 \mathrm{cc}$ olarak ölçüldü (Resim 1). Kemik sintigrafisinde de tutulum görülmedi. Hastaya tedavi seçenekleri anlatıldı ve sonuçta radikal prostatektomi planland1. Hastaya biyopsiden 8 hafta sonra radikal prostatektomi ve bilateral lenf nodu diseksiyonu uygulandi. Prostat volümünün büyüklügü nedeniyle puboprostatik ligamanların kesilmesi dorsal ven kompleksinin yeterli görüntüsünü sağlayamamıştır (Resim 2). $\mathrm{Bu}$ nedenle dorsal ven kompleksi dönülürken hem 1-0 vicryl sütür ile ' 8 rakamı' sütür atılmış hem de McDougall klemp ile venöz kompleks ve anterior üretra arasına girilerek ek sütür konulmuştur. Kompleksin diseksiyonu sırasında hastanın hidrasyonu kısılarak venöz pleksusun konjesyonu da azaltılmaya çalışılmıştır. Patolojik spesimenin sonucu prostat adenokarsinom Gleason skor 5+3 şeklinde raporlanmıştır. Tümör içinde yer yer 
perinöral invazyon dikkat çekmiştir, tümöral lezyon bir alanda kapsüler insizyon hattında devamlılık göstermektedir. Tümör 108 bloktan 13 tanesinde izlenmiş olup yaklaşık tümör volümü \%6 olarak hesaplanmıştır. On üç adet lenf nodu spesimeninin tamamı reaktif olarak raporlanmıştır. Perioperatif dönemde 1 ünite eritrosit süspansiyonu (ES) yapılan hastanın postoperatif hemoglobin $(\mathrm{Hb})$ seviyesi 11.3 $\mathrm{g} / \mathrm{dL}$ şeklindedir. Postoperatif 4.gün dreni çekilen hastanın totalde 400cc drenajı olmuştur. On üçüncü günde üretral sondası alınan hastanın postoperatif 1 . ay kontrolünde PSA seviyesi $0.01 \mathrm{ng} / \mathrm{mL}$ şeklindedir. Takipte olan hastanın günlük tek pedin kontinansı mevcut iken hasta empotan durumdadır.

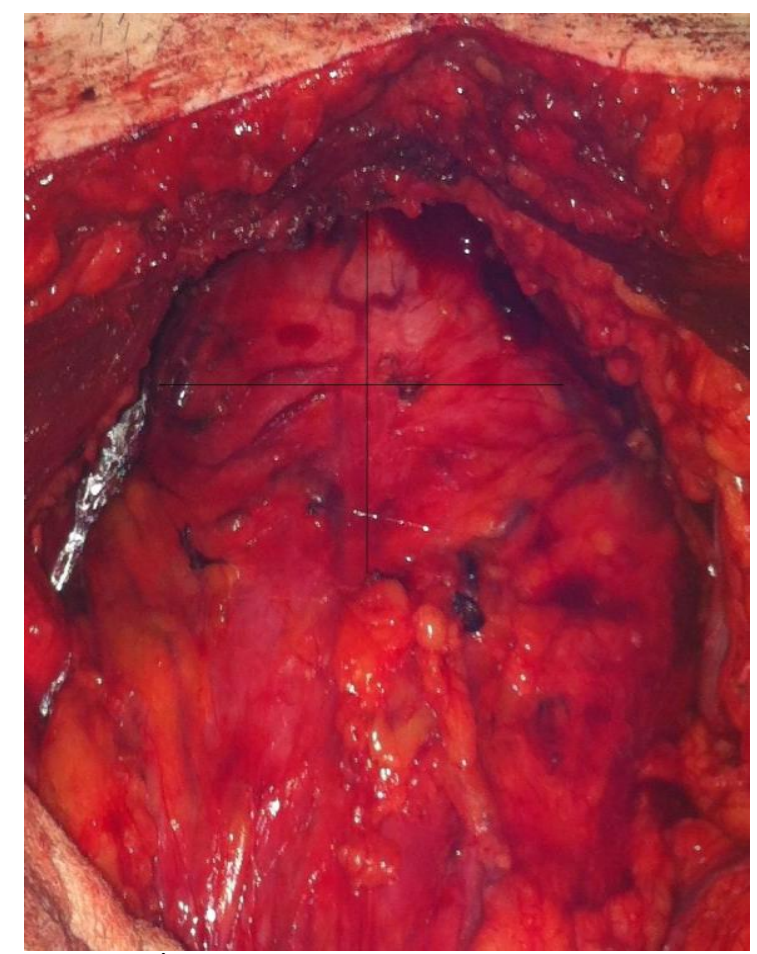

Resim 1: İntraoperatif görünüm

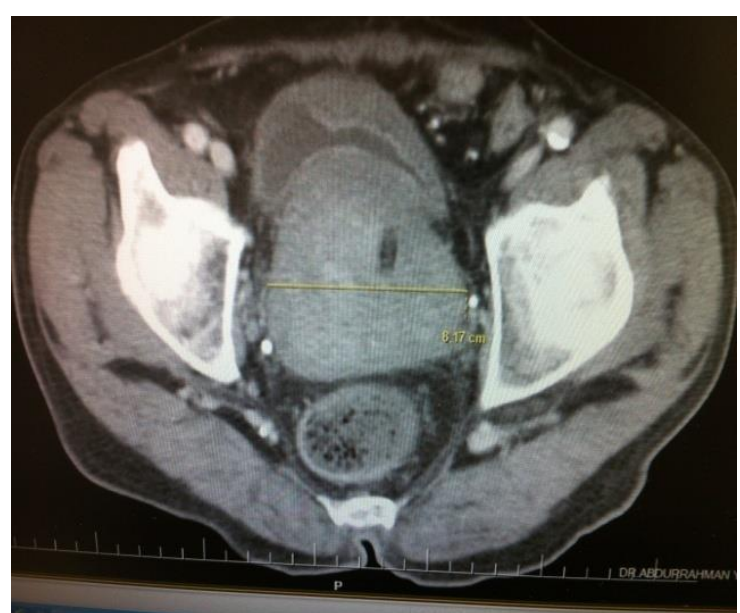

Resim 2: Tomografi görüntüsü

\section{Tartışma}

Lokalize prostat kanserinde tedavi modalitesinin belirlenmesinde prostat volümü önemli bir yere sahiptir. Büyük prostat varlığ cerrahi tercih edilecek hastalarda diseksiyonun zorlaşması ve nörovasküler demetin ortaya çıkarılmasındaki sıkıntılar nedeniyle kanama ve postoperatif empotans riskini artırmaktadır $(5,6)$. Prognozda preoperatif PSA seviyesi, Gleason skoru ve patolojik evrenin yanı sira prostat boyutu da belirleyicidir $(7,8)$. Literatürde tümör boyutu ile prognoz arasındaki ilişkiyi araştıran pek çok çalışma bulunmaktadır. Briganti ve ark. 3412 küçük prostat boyutlu olguda prognozun daha iyi olduğunu (9), Freedland ve Kulkarni de boyutun azalmasının cerrahi sınır pozitifliğini azalttığını göstermişlerdir $(10,11)$. D'amico büyük prostat varlığının preoperatif PSA seviyelerini artırdığını ancak cerrahi ve patolojik açıdan daha iyi sonuçlara sahip olduğunu belirtmiştir (12). Foley ve arkadaşları da 2003 yılındaki çalışmalarında prostat boyutunun büyümesi ile klinik önemsiz prostat kanseri saptanma olasılığının arttığını, büyük prostat volümünde PSA seviyelerinin yüksek olmasına rağmen biyopsideki Gleason skorlarının düşük olduğunu bunun da nedeninin yüksek prostat volümlü olgularda tümör volümünün daha düşük olmasına bağlanmaktadır (13). Çalışmaların büyük kısmında benzer sonuçlar yer almaktadır. Küçük volümlü olgularda tümörün daha agresif seyrettiği ve cerrahi sınır pozitifliğinin daha sık gözlendiği bildirilmekle birlikte büyük prostatın rekürrensle ilişkisinin bulunmadığ 
sadece cerrahi teknikte zorluğa yol açtığ 1 bildirilmiştir $(2,7,10,13)$. Olgumuzda da literatüre benzer olarak büyük prostat volümüne rağmen cerrahi sınır pozitifliği görülmemiş ancak cerrahinin zorluğuna bağlı nörovasküler demet korunamamıştır ve hasta postoperatif empotan durumdadir.

Sonuç olarak büyük prostat volümlü olgularda radikal prostatektomi cerrahisi tercih edilecekse cerrahi sınır pozitifliği ve biyokimyasal rekürrensle ilgili bir kaygıya gerek yoktur. Ancak cerrahi tekniğin zorluğu göz önünde bulundurularak preoperatif kan replasmanı hazır bulundurulmalı ve hastaya postoperatif inkontinans ve empotans riskinden özellikle bahsedilmelidir.

\section{Çıkar çatışmasıs: Yok}

\section{Kaynaklar}

1. Boyle P, Ferlay J. Cancer incidence and mortality in Europe 2004. Ann Oncol 2005;16:481-8

2. Oksay T, Ergün O, Hoşcan MB, Koşar A. The effect of prostate weight on the radical prostatectomy outcomes. J Clin Anal Med 2012;3(1):56-8

3. Siddiqui SA, Inman BA, Sengupta S, Slezak JM, Bergstralh EJ, Leibovich BC, et al. Obesity and survival after radical prostatectomy: A 10-year prospective cohort study. Cancer. 2006 1;107(3):5219

4. Hong SK, Chang IH, Han BK, et al. Impact of variations in bony pelvic dimensions on performing radical retropubic prostatectomy. Urology 2007;69: 907-11
5. Meraj S, Nagler HM, Homel P, Shasha D, Wagner JR. Radical prostatectomy: size of the prostate gland and its relationship with acute perioperative complications. Can J Urol 2003;10: 1743-8

6. Myers RP. Practical surgical anatomy for radical prostatectomy. Urol Clin North Am 2001; 28:473-90

7. Görgel SN, Şefik E, Balcı U, Girgin MC, Dinçel Ç. Prostat biyopsisinde kanser saptanan hastalarda prostat boyutu ve hasta yaşının prognostik faktörlerle ilişkisi. Turkish Journal of Urology 2012;38(3):1215

8. Aus G, Abbou CC, Bolla M, Heidenreich A, Schmid $\mathrm{HP}$, van Poppel $\mathrm{H}$, et al. EAU guidelines on prostate cancer. Eur Urol2005;48:546-51

9. Briganti A, Chun FK, Suardi N, Gallina A, Walz J, Graefen M, etal. Prostate volume and adverse prostate cancer features: fact not artifact. Eur J Cancer 2007;43:2669-77

10. Freedland SJ, Isaacs WB, Platz EA, Terris MK, AronsonWJ, Amling CL, et al. Prostate size and risk of high-grade, advanced prostate cancer and biochemical progression after radical prostatectomy: a search database study. J Clin Oncol 2005;23:754654

11. Kulkarni GS, Al-Azab R, Lockwood G, Toi A, Evans A, Trachtenberg J, et al. Evidence for a biopsy derived grade artifact among larger prostate glands. J Urol 2006;175:505-9

12. D'Amico AV, Whittington R, Malkowicz SB, Schultz D, Tomaszewski JE, Wein A. A prostate gland volume of more than $75 \mathrm{~cm} 3$ predicts for a favorable outcome after radical prostatectomy for localized prostate cancer. Urology 1998;52:631-6

13. Foley CL, Bott SR, Thomas K, Parkinson MC, Kirby RS. A large prostate at radical retropubic prostatectomy does not adversely affect cancer control, continence or potency rates. BJU Int 2003;92:370-4 